\title{
Electrochemical synthesis of p-type copper oxides
}

\author{
C. V. Niveditha, M. J. JabeenFatima, S. Sindhu* \\ Department of Nanoscience and Technology, University of Calicut, Kerala-673635, India \\ *sindhu.swaminath@gmail.com
}

PACS 82.45. Aa, 81.07.-b, 87.80Kc, 82.45Yz

DOI 10.17586/2220-8054-2016-7-4-747-751

Copper oxide is a narrow band gap, low cost, nontoxic, photoactive metal oxide and can be considered as the best candidate for photoelectrochemical applications. Thin films of p-type copper oxide are prepared by cyclic voltammetric technique. The electrochemical method is a cost effective low temperature technique for the preparation of functional thin films. Tools like, GIXRD, Raman Spectroscopy, UV-Vis Spectroscopy, PL, SEM and EIS analysis are done to study the structure, phase, optical, morphological and electrochemical behavior of the copper oxide thin film. The effect of deposition conditions on the electrical and optical properties of the thin films are analyzed in detail.

Keywords: cyclic voltammetry, electrochemical impedance analysis.

Received: 14 February 2016

Revised: 26 April 2016

\section{Introduction}

Copper oxide is a low cost, non-toxic, narrow band gap metal oxide [1]. Oxides of copper crystallize mainly in two forms, cuprous oxide $\left(\mathrm{Cu}_{2} \mathrm{O}\right)$ and cupric oxide $(\mathrm{CuO})[1,2]$. Cuprous oxide is a direct bandgap [1] and cupric oxide is an indirect band gap [1] metal oxide. These metal oxides exhibit interesting properties suitable for catalytic [3], electrochromic [4], electrochemical [4], photoelectrochemical [5] and photovoltaic applications [4]. Due to the narrow band gap $\left(\mathrm{Cu}_{2} \mathrm{O}-1.9-2.2 \mathrm{eV}\right.$ and for $\mathrm{CuO}$ is $\left.1.2-1.7 \mathrm{eV}\right)$ it has high potential in photovoltaic and photoelectrochemical applications. Commonly, copper oxide films have been synthesized by the high temperature thermal oxidation of copper metal [6] that limits the control over the interfacial features like surface area, particle size, and grain boundaries etc, which affect the optical and electrochemical properties. Hence, the present study focus on electrodeposition method [7] which is an attractive method for thin film synthesis under low temperature conditions. The efficiency of electronic and charge transfer mechanism between the nanoparticles or the nanoparticles and the adjacent layer depends highly on the shape and size of the particles participating in the process. This highlights the significance of deposition of size and shape controlled nanostructures by electrochemical deposition.

\section{Experimental method}

Electrodeposition of copper oxide is done using three electrode system, where cleaned FTO is used as the working electrode, platinum wire as counter electrode and $\mathrm{Ag} / \mathrm{AgCl}$ as reference electrode. $\mathrm{The} \mathrm{Cu}_{2} \mathrm{O}$ is deposited on the FTO substrate under neutral $\mathrm{pH}$ the potential is swept between $0 \mathrm{~V}$ to $-0.8 \mathrm{~V}$ from the solution containing $5 \mathrm{mM} \mathrm{CuSO}_{4}$ and $50 \mathrm{mM} \mathrm{KNO} 3$ and repeat the cycles three times to get a yellow colored film. The $\mathrm{CuO}$ is deposited from solution containing $5 \mathrm{mM} \mathrm{CuSO}_{4}$ and $50 \mathrm{mM} \mathrm{KNO}_{3}$ under acidic $\left(2.5 \mathrm{mM} \mathrm{H}_{2} \mathrm{SO}_{4}\right) \mathrm{pH}$ the potential is swept between $0 \mathrm{~V}$ to $-0.8 \mathrm{~V}$ and repeat the cycles three times to obtain a black colored film. Fig. 1 shows the photographs of the obtained yellow and black films of copper oxides.
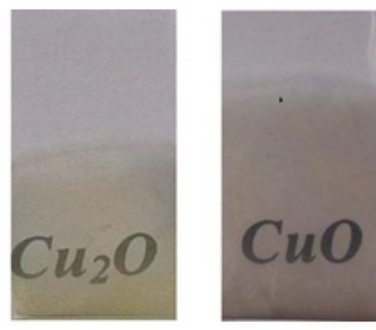

FIG. 1. Photographs of $\mathrm{Cu}_{2} \mathrm{O}$ and $\mathrm{CuO}$ films 


\section{Result and discussion}

\subsection{Cyclic voltammetry}

Figure 2 depicts the cyclic voltammogram for the electrodeposition of both $\mathrm{Cu}_{2} \mathrm{O}$ and $\mathrm{CuO} . \mathrm{Cu}_{2} \mathrm{O}$ formed under neutral pH. In Fig. 2(a), the peak at $-0.21 \mathrm{~V}$ shows the film formation and there are two peaks at Fig. 2(b) shows the conversion of $\mathrm{Cu}^{2+}$ ion from $\mathrm{Cu}^{+}$ion i.e, the formation of $\mathrm{CuO}$. $\mathrm{The}^{\mathrm{Cu}^{2+}}$ ion accepts an electron from the electrode and becomes a $\mathrm{Cu}^{+}$ion to attain a stable electronic configuration. The positive nature of the metal ion helps, forming weak Van der Waals interactions with the non-bonded electrons of oxygen atom of the water and the adsorbed $\mathrm{Cu}-\mathrm{H}_{2} \mathrm{O}$ complex on FTO substrate is neutralized by releasing $\mathrm{H}^{+}$ion, which resulted in the deposition of $\mathrm{Cu}_{2} \mathrm{O}$. An increase in cathodic current is found near a cathodic potential of $-0.21 \mathrm{~V}$, indicating the deposition of $\mathrm{Cu}_{2} \mathrm{O}$ film. When the cycle is repeated, the deposition current diminishes with an increase in film coverage on the substrate, since $\mathrm{Cu}_{2} \mathrm{O}$ is less conducting than FTO. But at acidic $\mathrm{pH}$, the $\mathrm{H}^{+}$ion from $\mathrm{H}_{3} \mathrm{O}^{+}$ ion complex reduced by accepting electron from $\mathrm{Cu}^{+}$ion, leads to the formation of $\mathrm{Cu}^{2+}$ ion which is the then converted into $\mathrm{CuO}$.
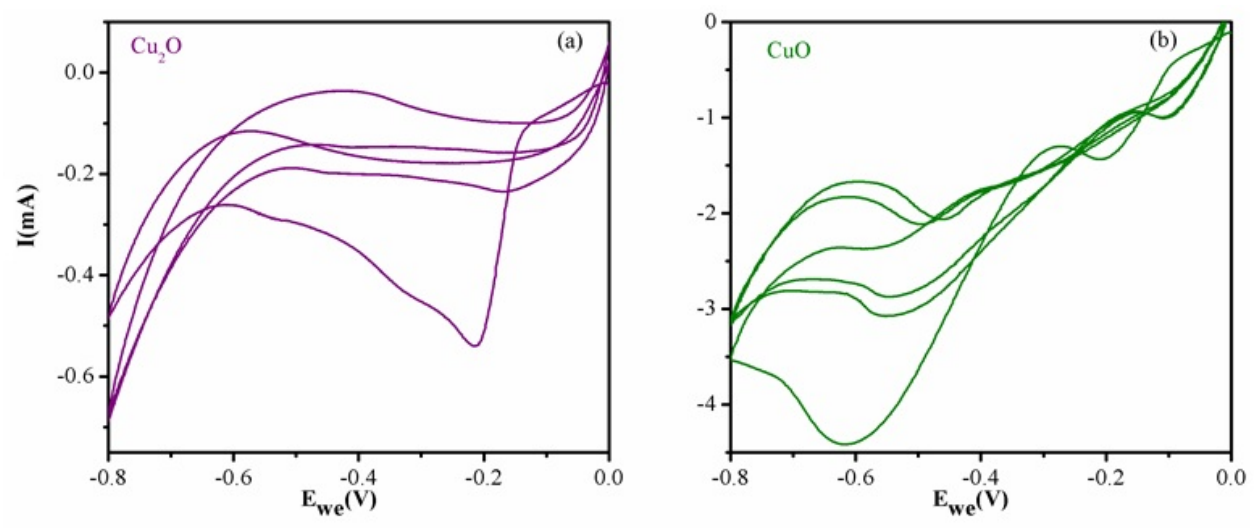

FIG. 2. Cyclic voltammogram of electrodeposition of (a) $\mathrm{Cu}_{2} \mathrm{O}$ and (b) $\mathrm{CuO}$

\subsection{Structural analysis}

The crystallinity of the deposited films was analyzed using a grazing angle X-ray diffraction (GIXRD). Fig. 3 depicts the XRD spectra of the deposited films and is compared with standard JCPDS files 78-2076, 80-1917, which correspond to cubic and monoclinic crystal structures respectively for cuprous and cupric oxide of space groups $\mathrm{Pn} 3 \mathrm{~m}$ and $\mathrm{C} 1 \mathrm{c} 1$. In cubic $\mathrm{Cu}_{2} \mathrm{O}$, the copper atoms are at fcc sub lattices and oxygen atoms are at bcc sub lattices [8]. In the case of monoclinic $\mathrm{CuO}$, the copper atom is coordinated by four oxygen atoms in an approximately square planar configuration and the oxygen is coordinated to four copper atoms at the corners of a distorted tetrahedron [9].
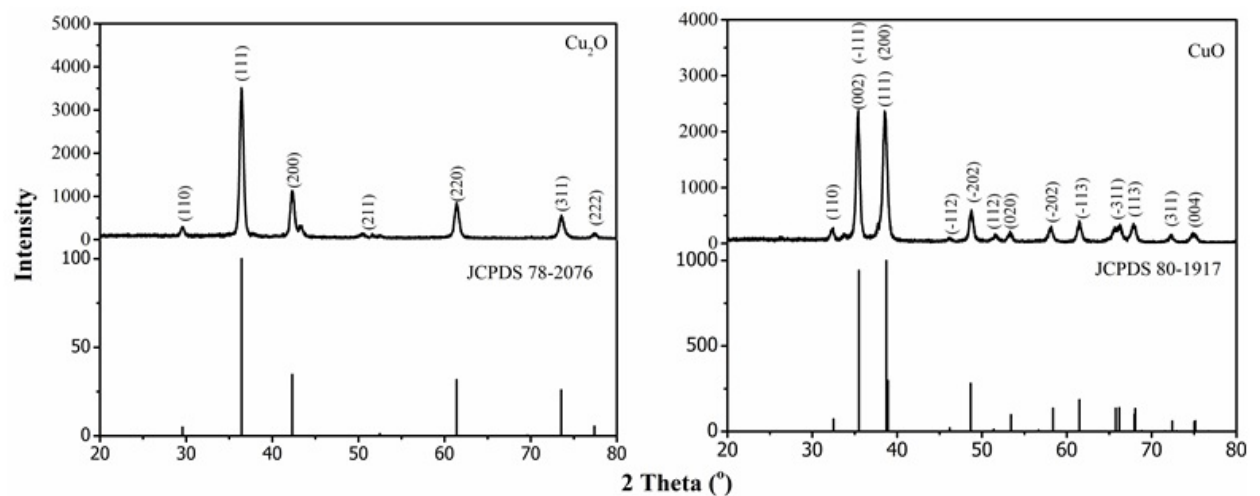

FIG. 3. XRD spectra of $\mathrm{Cu}_{2} \mathrm{O}$ and $\mathrm{CuO}$ films compared with standard JCPDS 


\subsection{Morphology}

The morphology of the film obtained from SEM analysis. Fig. 4 depicts the average size of $\mathrm{Cu}_{2} \mathrm{O}$ is $75 \mathrm{~nm}$ and that of $\mathrm{CuO}$ is $93 \mathrm{~nm}$. The morphology of $\mathrm{Cu}_{2} \mathrm{O}$ is square in shape, while that of $\mathrm{CuO}$ is spherical shape.
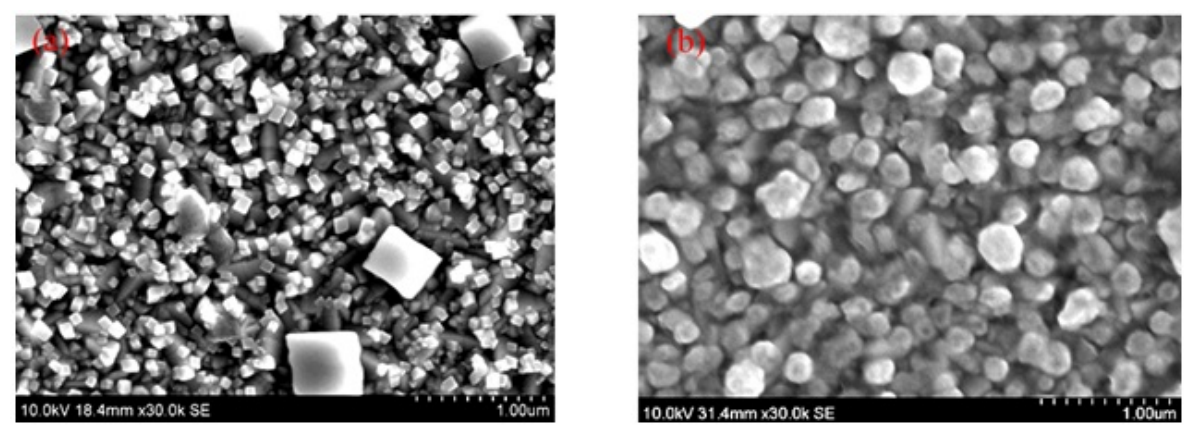

FIG. 4. SEM image of $\mathrm{Cu}_{2} \mathrm{O}$ and $\mathrm{CuO}$ films

\subsection{Optical properties}

Optical properties of the films were analyzed by using UV-Visible spectroscopy. The absorption spectra and Tauc plots for $\mathrm{Cu}_{2} \mathrm{O}$ and $\mathrm{CuO}$ are shown in Fig. 5. The band gap is estimated from the Tauc plot and the obtained values are $2.43 \mathrm{eV}$ and $1.73 \mathrm{eV}$ respectively for $\mathrm{Cu}_{2} \mathrm{O}$ and $\mathrm{CuO}$. The PL spectra give idea about the defect state. Fig. 6 depicts three peaks in the PL spectra corresponding to band edge emission, oxygen ion vacancy and copper ion vacancy [10]. The band edge emission is slightly red shifted (562 nm) in the case of cupric oxide than cuprous oxide $(527 \mathrm{~nm})$. All the defect emissions are also red shifted. The p-type nature of the films is due to the presence of copper ion vacancies.
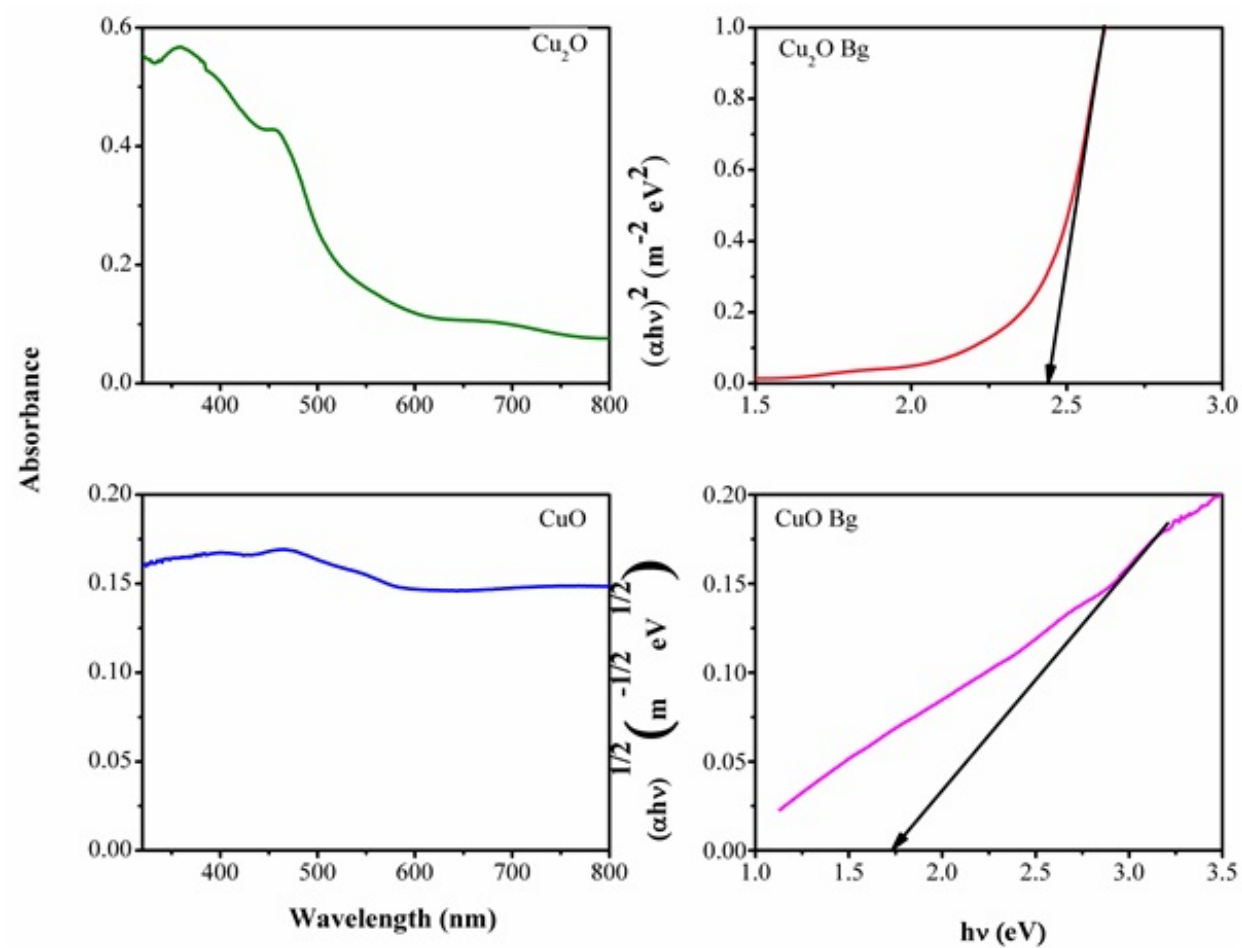

FIG. 5. UV-Visible spectra and Tauc plot of $\mathrm{Cu}_{2} \mathrm{O}$ and $\mathrm{CuO}$ films 

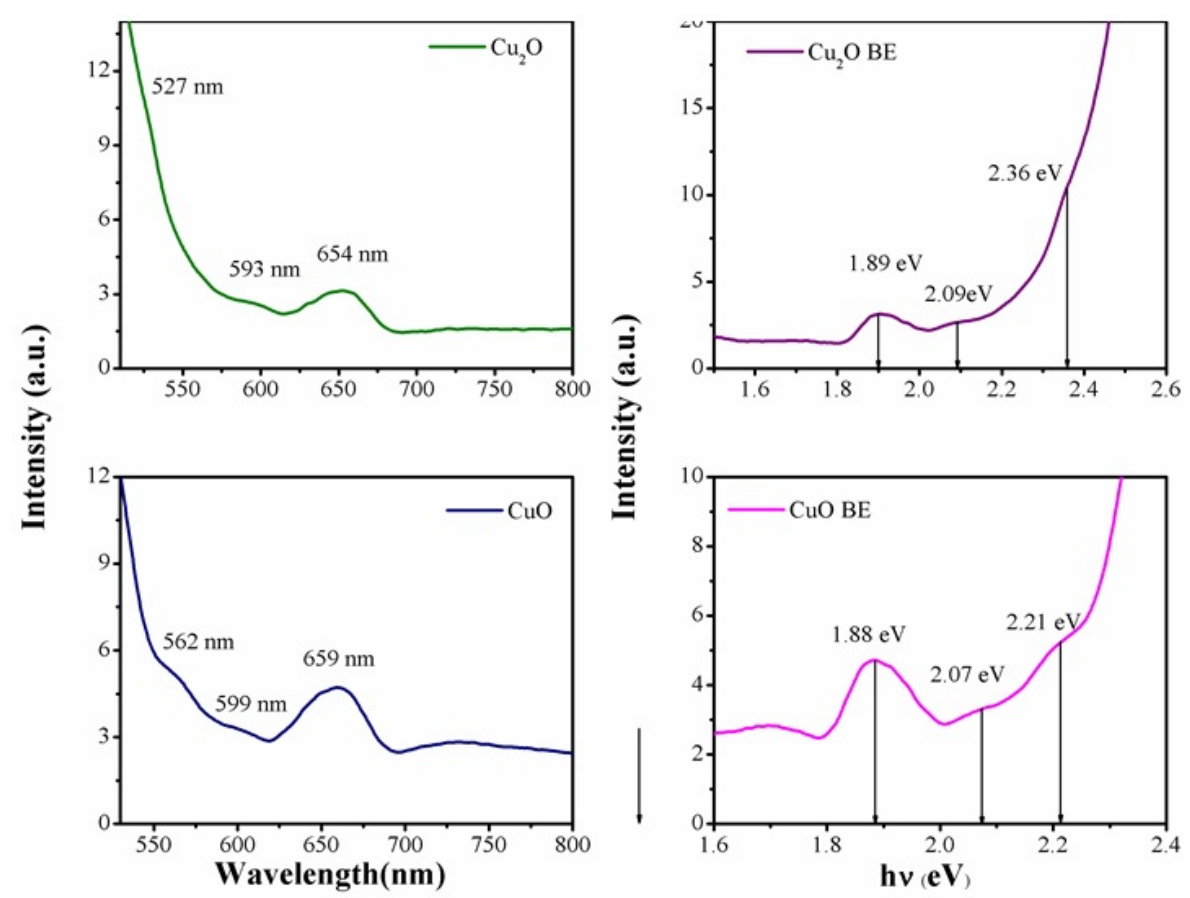

FIG. 6. PL spectra of $\mathrm{Cu}_{2} \mathrm{O}$ and $\mathrm{CuO}$ films

\subsection{Electrical properties}

The electronic properties of the films are studied using hall measurement system. From this measurement both $\mathrm{Cu}_{2} \mathrm{O}$ and $\mathrm{CuO}$ are p-type semiconductors with conductivity of $4.71 \times 10^{2} \mathrm{Scm}^{-1}$ and $4.12 \times 10^{3} \mathrm{Scm}^{-1}$ respectively. Fig. 7. depicts the Nyquist plots obtained from electrochemical impedance (EIS) analysis of copper oxides, which measure the interfacial resistance between the electrode and electrolyte in the dark and light condition. This analysis confirms the photo activity of copper oxide. $\mathrm{Cu}_{2} \mathrm{O}$ is more photoactive than $\mathrm{CuO}$.
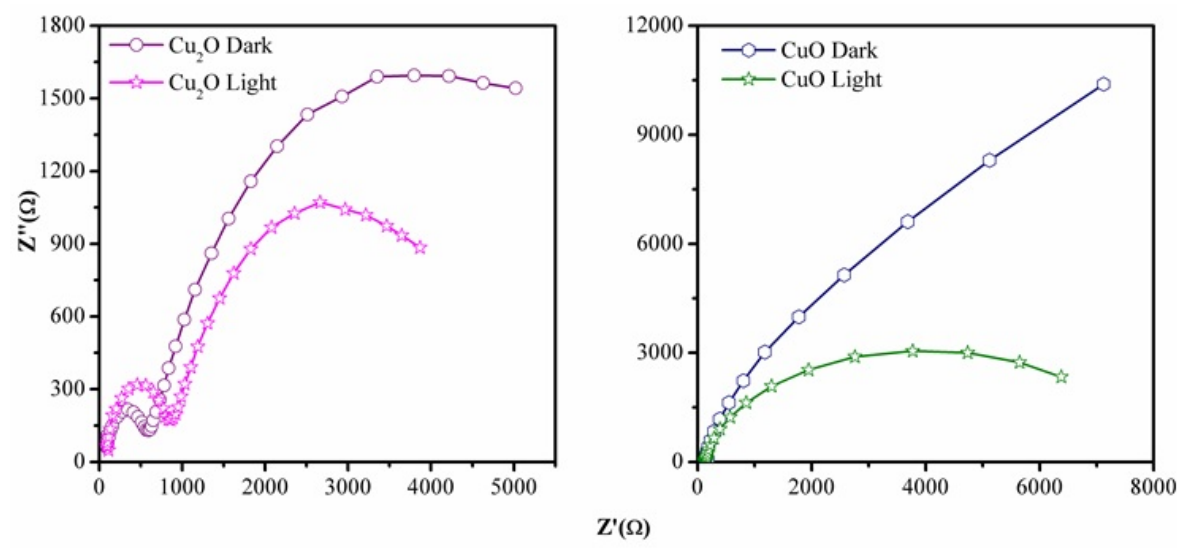

FIG. 7. Nyquist plots of electrodeposited $\mathrm{Cu}_{2} \mathrm{O}$ and $\mathrm{CuO}$ films

The efficiency of the cell was obtained from chronoamperometric analysis in $0.1 \mathrm{M} \mathrm{Na}_{2} \mathrm{SO}_{4}$ electrolyte by using three electrode system where deposited film was a working electrode, Pt wire was a working electrode and $\mathrm{Ag} / \mathrm{AgCl}$ was the reference electrode. The efficiency is calculated from equation 1, where $\eta$ is the efficiency of the cell, $I$ is the steady current density obtained from I-t curves (shown in Fig. 8), $V$ is the applied potential $-0.2 \mathrm{~V}$ and $J_{\text {Light }}$ is the irradiance intensity of $100 \mathrm{~mW} / \mathrm{cm}^{2}$. The efficiencies obtained for $\mathrm{Cu}_{2} \mathrm{O}$ and $\mathrm{CuO}$ were $0.5 \%$ and $0.2 \%$ respectively.

$$
\eta=\frac{I(1.23-V)}{J_{\text {Light }} \cdot 100} .
$$




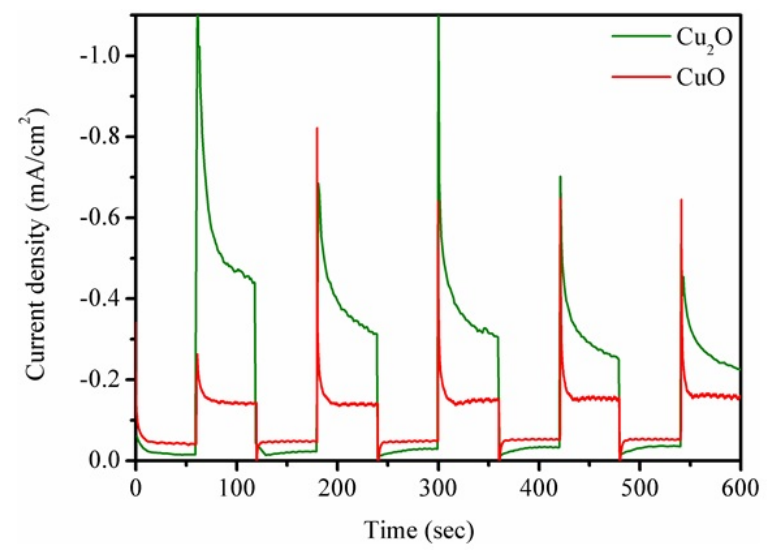

FIG. 8. Chronoamperometric spectra of electrodeposited $\mathrm{Cu}_{2} \mathrm{O}$ and $\mathrm{CuO}$ films

\section{Conclusion}

Cyclic voltammetric deposition techniques were utilized to synthesize p-type copper oxides at potentials ranging from $0 \mathrm{~V}$ to $-0.8 \mathrm{~V}$ at a scan rate of $20 \mathrm{mV} / \mathrm{s}$. $\mathrm{Cu}_{2} \mathrm{O}$ is formed under neutral $\mathrm{pH}$ and $\mathrm{CuO}$ is formed at lower $\mathrm{pH}$ values. The band gaps of both copper oxides are narrow ie; $2.43 \mathrm{eV}$ and $1.73 \mathrm{eV}$ for $\mathrm{Cu}_{2} \mathrm{O}$ and $\mathrm{CuO}$ respectively. The p-type nature is confirmed from Hall measurement system. Both are p-type copper oxides. The electrochemical impedance analysis shows that the cuprous oxide thin films are more photoactive than cupric oxide, which was confirmed through chronoamperometric analysis. The efficiencies of $\mathrm{Cu}_{2} \mathrm{O}$ and $\mathrm{CuO}$ were $0.5 \%$ and $0.2 \%$ respectively.

\section{Acknowledgement}

Authors Niveditha C.V. and Jabeen Fatima acknowledge CSIR for financial assistant in the form of Senior Research Fellowship. Sindhu S acknowledges Kerala State Council for Science Technology and Environment (KSCSTE), Govt. of Kerala, and Council of Scientific and Industrial Research (CSIR), Govt. of India for financial assistance. Support obtained from Satyabhama University, Chennai and NIT Calicut for GIXRD and SEM analysis are greatly acknowledged.

\section{References}

[1] Kari E.R.B., Kyoung-Shin C. Electrochemical synthesis and characterization of transparent nanocrystalline $\mathrm{Cu}_{2} \mathrm{O}$ films and their conversion to $\mathrm{CuO}$ films. ChemComm, 2006, P. 3311-3313.

[2] Samarasekara P. Characterization of low cost p-Cu $2 \mathrm{O} / \mathrm{n}-\mathrm{CuO}$ junction, GESJ.: Physics, 2010, 2(4), ISSN-1512-1461.

[3] Yongqian W., et al. Controllable fabrication nanostructured copper compound on Cu substrate by one-step route. RSC.Adv., 2015 , P. 1-17.

[4] Ahmad S.Z., et al. Nanostructured copper oxide semiconductor: a perspective on materials, synthesis method and applications. J. Mater. Chem. C., 2014, 2, P. 5247.

[5] Chia-Yu L., et al. $\mathrm{Cu}_{2} \mathrm{O} / \mathrm{NiO}_{x}$ nanocomposite as an inexpensive photocathode in photoelectrochemical water splitting. Chem. Sci., 2012.

[6] Kasim U.I., et al. Effect of oxidation temperature on the properties of copper oxide thin films prepared from thermally oxidised evaporated copper thin films. IOSR-JAP, 2013, 3, P. 61-66.

[7] Rachel O., Usha R., Sajeeviraja. Characteristics of electron beam evaporated and electrodeposited $\mathrm{Cu}_{2} \mathrm{O}$ thin films-comparative study. Int. J. Electrochem. Sci., 2012, 7, P. 8288-8298.

[8] Reimann K., Syassen K. Raman Scattering and Photoluminescence in $\mathrm{Cu}_{2} \mathrm{O}$ under Hydrostatic Pressure. Phys. Rev. B, 1989, 39, P. 1111311119.

[9] Ahmad S.Z., Rozina A.R., Anthony J.M., Anthony P.O., Kourosh K. Nanostructured Copper Oxide Semiconductors: A Perspective on Materials, Synthesis Methods and Application. J. Mater. Chem. C, 2014, 2, P. 5247-5270.

[10] Jiji K., Soosen S.M., Anoop C., George K.C. Optical Properties of CuO Nanoparticles. AIP Conf. Proc., 2011,1391 , P. 576-578. 